\title{
Effect of Treadmill Training on Energy Cost of Walking, Functional walking capacity and Postural Stability in Children with Cerebral Palsy:A Randomized Controlled Trial
}

Walaa Abd El-hakiem Abd El-nabie* and Amira Mahmoud Abd El-Monem

*Correspondence: dr.walaapt@yahoo.com

CrossMark

$\leftarrow$ Click for updates

Lecturer at Physical Therapy for Pediatrics Department, Faculty of Physical Therapy, Cairo University, Egypt.

\begin{abstract}
Background: Independent efficient ambulation and postural stability are two main objectives in the rehabilitation program for children with cerebral palsy $(\mathrm{CP})$.

Purpose: The purpose of the present study was to investigate the effect of treadmill training on energy cost of walking, functional walking capacity and postural stability in children with hemiplegic CP.

Method: Fifty-one (30 boys and 21 girls) children with hemiplegic CP with their ages ranged from eight to ten years were included. They were randomly classified into two groups; experimental and control groups. Both groups received designed physical therapy programs, while,the experimental group received treadmill training program instead of traditional gait training, at a frequency of three times per week for three months. Pre and post- treatment assessment of energy cost of walking (energy expenditure index), functional walking capacity (6- minutes walking test) and postural stability via pediatric reaching test (anterior and lateral reaching tests) were conducted.

Results: Both groups showed; significant increase in 6- minutes walking test, anterior and lateral reaching tests $(\mathrm{p}<0.001)$ and significant decrease in energy expenditure index $(\mathrm{p}<0.001)$ after treatment protocols. The significant improvement after treatmentin all measured variables was obtained in favor to experimental group $(\mathrm{p}>0.001)$.
\end{abstract}

Conclusion: Treadmill training may improve energy cost of walking, functional walking capacity and postural stability in children with hemiplegic CP.

Keywords: Cerebral palsy, Energy cost of walking, Hemiplegia, Postural stability, Treadmill training, Walking capacity

\section{Introduction}

A common cause of motor impairments among children is $\mathrm{CP}$, which is caused by damage in the brain occurring before, during or immediately after birth. It is also, often characterized by group of developmental motor and postural disorders [1]. Motor disorders affecting children with $\mathrm{CP}$ allow them to walk with slower speed and higher energy expenditure (EE), than age-matched children without $\mathrm{CP}[2,3]$. Spastic hemiplegia is a unilateral paralysis which represents $20 \%$ to $30 \%$ of all types of CP. In children with hemiplegia, motor impairments predominate in the upper limbs that restrict the functional activity and overall independency while, foot inversion and planter flexion are most common impairments in the lower limbs $[4,5]$.

Motor impairments such as; spasticity, motor control deficit and joint contractures which affect children with CP may lead to an increase in energy cost $(\mathrm{EC})$ of walking and consequently 
inefficient gait $[6,7]$. Gait deviations in children with CP cause increase in EC of walking by two-fold, in compared with typically developing children [8-11]. The energy expenditure index (EEI) method can be used to assess EC of walking indirectly in children with hemiplegic CP [12]. Johnston et al. [13] conducted a study to compare the EC of walking that was measured by EEI between normal and CP children. They concluded that, heart rate $(\mathrm{HR})$ is an accurate approach that can be used to assess EE indirectly in children with $\mathrm{CP}$ who demonstrated higher EC of walking than normal children. Therefore, interventions that are designed to improve functional mobility by addressing gait deviationsand reducing EC of walking are essential treatment approaches to enhance independent functioning [14].

Children with CP suffer from deteriorated walking capacity which results from muscle spasm, joint deformity and lowered level of physical fitness [15]. Most of ambulatory children with $\mathrm{CP}$ loss their walking capacity, or at least have a deteriorated level of it as they become older [16].

Postural stability is an important factor in keeping up functional activities as; it influences gross motor capabilities [17]. It depends on the integration between nervous and musculoskeletal systems, they transfer vestibular, somatosensory and visual informations [18]. This integration is impaired in children with hemiplegia and causes dysfunction in postural control and consequently may result in postural instability [19].

Treadmill training is a familiar therapeutic procedure used in the rehabilitation program of children with CP. It allows such children to walk with a proper walking pattern by processing the repeated sensory information acquired during walking $[20,21]$. A treadmill protocol can be applied with or without body weight support; it provides a training of specific task with repetition of the gait cycle [21]. Therefore, the aim of this study was to explore the effect of treadmill training on EC of walking, functional walking capacity and postural stability in children with hemiplegic CP. It was hypothesized that, treadmill training would improve EC of walking, functional walking capacity and postural stability in children with CP.

\section{Subjects and procedures Subjects}

A sample of fifty-one children with hemiplegic CP of both sex agreed to participate in the present study with their ages ranged from eight to ten years. They were selected from the Outpatient Clinic of Faculty of Physical Therapy, Cairo University. They had a diagnosis of hemiplegia that was obtained from their medical records and confirmed by radiological examination and neurologist. The degree of spasticity of elbow flexor and knee extensor muscles ranged from 1 to $1+$ according to Modified Ashwarth Scale [22]. The children were at level II on Gross Motor Function Classification System(GMFCS) [23] and able to follow instructions of evaluation and treatment procedures. Participants were excluded if they had any of the following; fixed deformities in upper and lower extremities, spinal or postural deformities, previous orthopedic operations or botulinum toxin injection in the past one year prior to the current study, walking with any type of lower limb orthosis and/or cardiac problems. At the study duration, participants did not receive any intervention modalities to enhance the performance of lower extremities except the intervention that was prescribed in the current study. Approval by the Ethical Committee of the Faculty of Physical Therapy, Cairo University, and written consent forms from parents of children, were obtained at the beginning of the study.

\section{Sample size}

Power analysis was conducted to determine the appropriate sample. Estimates of the mean and standard deviation of the EEl were collected from a pilot study including 12 children who were received the same intervention $(M 1=1.085, S D 1=0.22$ and $\mathrm{M} 2=0.85, \mathrm{SD} 2=0.18$ ), alpha level of 0.05 , power of $90 \%$, and effect size of 1.16 . These assumptions created a total sample size of 28 children ( 14 for each group). We increased the sample size to fifty-one children.

\section{Design, Randomization and blinding}

This study was a blind randomized controlled trail that was conducted from December 2016 to March 2018. Fifty-eight hemiplegic children were screened for participation in the current study. Five children were excluded as they didn't fit with inclusion criteria and also,three children refused to participate. The remaining fifty-one children were randomly allocated into two groups; the control group who received a designed physical therapy program and the experimental group who received the same program combined with treadmill training instead of traditional gait training exercises. The way of randomization was sealed envelopes, each envelop contained a sheet of paper that showed the child was either in the experimental or control groups. The process of randomization was performed by an independent person who was blinded to the purpose or protocol of the study. Flow of participants was demonstrated through a flow chart which based on Consolidated Standards of Reporting Trials (CONSORT) (Figure 1).

\section{Procedures}

\section{A-Outcomes measures}

Children of both groups were assessed prior to and immediately after treatment protocols.Assessment procedures were carried out by the same examiner (who was blinded to subjects allocation) and included the evaluation of; EC of walking (EEI), functional walking capacity (6MWT) and postural stability (anterior and lateral reaching tests).

\section{1-Energy cost of walking}

Energy expenditure index (EEI) is a method used to evaluate $\mathrm{EE}$ and $\mathrm{EC}$ of walking indirectly by correlating the changes in

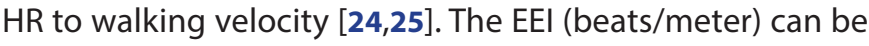
calculated as; walking HR (beats/min) minus resting HR (beats/ min)on walking velocity (meters/min) [26]. Each child was 


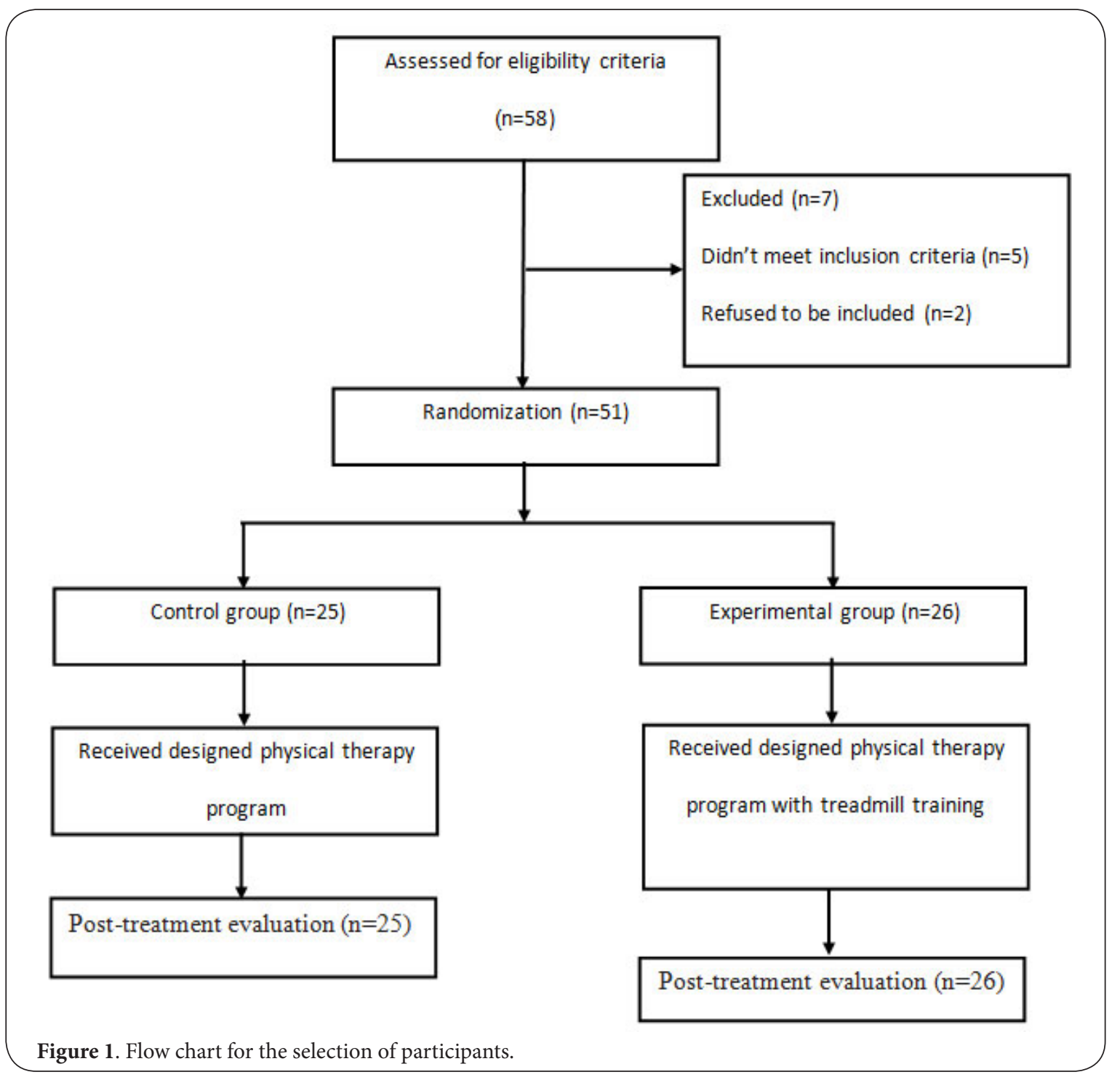

instructed to avoid food intake for at least two hours before the test to avoid thermo genic effect of food on $\mathrm{EE}$, and to wear comfortable clothes. For the assessment of EEl, resting HR was obtained for each child during comfortable sitting position for 5 minutes by using pulse oximeter which was attached to the child's index finger. Walking HR and speed was obtained immediately following a walking test (with a comfortable speed) for duration of 5 minutes in a walkway [27]. EEI was then calculated from the following equation: walking HR-resting HR/walking speed.

\section{2- Functional walking capacity}

The 6-minute walk test is a simple, standardized walking test used to evaluate the functional ability in children with CP [28]. It is easy to be applied, well tolerated, and more reflective of daily life activities and functional capacity than other walking tests [29]. 6MWT is a high reliable test $(r$ value $=0.955$ and $P$ value $<0.0001$.) that can be used in ambulatory children with spastic CP; it provides clinical information concerning gait capabilities [30]. Children in both groups completed the test as illustrated in the American Thoracic Society (ATS) statement [31]. Evaluation procedures took place on a flat hard surface of a thirty-meter long straight corridor, without any obstacles and each child was allowed to use his comfortable footwear. Verbal instructions or words of encouragement that allowed by the ATS guideline were given to all participants during the test procedure which permits one comment every minute. Before the beginning of test procedures, children were informed that "the purpose of the test is to walk for 6 minutes as far as possible." The evaluator walked behind the child during the test to guard him but without affecting his speed. At the end of test, the distance in meter that the child 
covered it was recorded.

\section{3-Postural stability}

Pediatric reaching test (PRT) is a reliable test (inter-tester reliability and test-retest reliability ranged from intraclass correlation coefficients of 0.50 to 0.93 and 0.54 to 0.88 , respectively). It is used for evaluating postural stability in both lateral and anterior directions and, it can be applied easily for children with CP $[32,33]$. Also, it is used to assess dynamic balance and the capability to control sideways of the body within stability limits during reaching. PRT measures maximum distance that the child reaches to it beyond his arm length without moving his foot though a ruler fixed to the wall [34,35]. Before testing, the task was demonstrated to each child and he/she was attached by a sheet of paper to the floor, and traced his foot position without socks and shoes. The testing trail was repeated if the child took a step or touched the evaluator [36].

\section{Anterior reaching test}

Each child was asked to maintain his right shoulder at 90 degrees of forward flexion, with the elbow extended and the wrist in neutral position for three seconds. The initial reading was taken by the evaluator who stood behind the child by using a flexible tape. The child was asked to reach forward as far as he/she could, and holding this position for three seconds then the distance was measured from this final position. Initial and final readings were taken from the level of child's acromion to the tip of middle finger.The difference between initial and final positions was calculated. The mean of three trials was taken according to Bartlett and Birmingham, 2003 [32].

\section{Lateral reaching test}

The initial position of right shoulder was maintained at 90 degrees of abduction, with the elbow extended and neutral position of the wrist. Then each child was instructed to reach laterally as far as he/she could. Measurements of distance at both positions and difference between them were the same as in anterior test.

\section{B- Treatment procedures}

Treatment procedures of both groups were carried out at the Outpatient Clinic of Faculty of Physical Therapy, Cairo University.

\section{-For control group}

The children received a designed physical therapy program. It was individualized, according to the child's abilities and conducted for three times per week over twelve consecutive weeks. The treatment program involved the following sets of exercises (each one set of exercises took approximately from 15 to 20 minutes per session); mat, balance, functional motor exercises and gait training. Mat exercises included; stretching of tight muscles, strengthening of antispastic muscles and physical therapy modalities to reduce spasticity. Functional motor exercises involved; stair climbing and weight-bearing activities. Balance exercises and gait training included; balance activities from standing, step sideway, forward and backward and walking between parallel bars with and without obstacles [37].

\section{-For experimental group}

Children in this group received the same program as control group except gait training exercise was replaced by treadmill training program. The treatment program was conducted at frequency of three times per week over twelve consecutive weeks [38,39]. A motorized treadmill (Medical and Industrial Instrument and supplies. S.N. 04065, model 770 CE, Italy) which had a minimum speed of $0.1 \mathrm{~km} / \mathrm{h}$ and increments of $0.1 \mathrm{~km} / \mathrm{h}$ was used in this study. The children were instructed to look forward, and to hold hand rails of the treadmill during walking at first sessions until they were able to walk without support. Each training session consisted of three phases; warming-up, training and cooling-down. The warming-up phase consisted of 5 minutes of static stretching of iliopsoas, hamstring and calf muscles [40]. In the training phase, each child walked on the treadmill first at slowest speed of $0.1 \mathrm{~km} / \mathrm{h}$ and then the speed increased gradually to a level at which the child stepped forward in a comfortable way [41]. Initial treadmill sessions consisted of three 10-minutes of treadmill walking interspersed with periods of five-minute rest. However,in subsequent sessions, periods of rest were individualized, and children were permitted to walk continuously on the treadmill if they could do this, up to 30 minutes. Generally, the duration of treadmill walking was 30 minutes, with two periods of rest [42].

During treadmill walking, verbal or even tactile feedbacks were provided if abnormal gait pattern appeared (i.e., scissoring of lower extremities). Gradually, these feedbacks decreased and replaced by active corrected movements. Instructions regarding the maintenance of proper upright posture, heel strike at initial contact and knee extension during stance phase were essential during the treadmill training [42]. The treatment session was finished earlier if the child suffered from pain or difficulty in breathing or if he stopped stepping forward. Finally, the cooling-down phase consisted of five minutes of stretching exercises of iliopsoas, hamstring and calf muscles. Over the duration of treatment, logbooks were kept to document; numbers of sessions, speed of treadmill and any problems that happened during the treatment (e.g., soreness and fatigue).

\section{Data analysis}

Subject characteristics were compared between both groups using t-test. Chi- squared test was used for comparison of sex distribution between groups. Normal distribution of data was checked using the Shapiro-Wilk test for all variables. Levene's test for homogeneity of variances was conducted to test the homogeneity between groups. Mixed MANOVA was performed to compare the effects of treatment on EEI, 6MWT, anterior and lateral reaching tests between the experimental and control 
groups as between group comparison and between pre and post treatment in each group as within group comparison. Post-hoc tests using the Bonferroni correction were carried out for subsequent multiple comparison. The level of significance for all statistical tests was set at $p<0.05$. All statistical analysis was conducted through the statistical package for social studies (SPSS) version 19 for windows (IBM SPSS, Chicago, IL, USA).

\section{Results}

\section{Subject characteristics}

Table 1 showed the subject characteristics of both groups. There was no significant difference between both groups in the mean age, weight, height and BMI. $(p<0.05)$. Also, there was no significant difference in sex distribution between groups $(p=0.68)$.

\section{Effect of treatment on EEI, 6MWT, anterior and lateral reaching tests}

Mixed MANOVA revealed that there was a significant interaction of treatment and time (Wilks' Lambda $=0.27 ; F(4,46)=30.09$, $\mathrm{p}=0.0001$ ). There was a significant main effect of time (Wilks' Lambda $=0.02 ; F(4,46)=501.49, p=0.0001)$. There was a significant main effect of treatment (Wilks' Lambda $=0.41 ; F(4,46)=16.18$, $\mathrm{p}=0.0001$ ). Table 2 showed descriptive statistics of EEl, 6MWT, anterior and lateral reaching tests as well as the significant level of comparison between groups and the significant level of comparison between pre and post treatment in each group.

\section{Within group comparison}

Both groups showed significant decrease in EEl post treatment compared with that pre treatment $(p<0.001)$. Also, there was a significant increase in $6 \mathrm{MWT}$, anterior and lateral reaching tests post treatment compared with that pre treatment $(p<0.001)$. (Table 2).

\section{Between group comparison}

There was no significant difference between experimental and control groups in all variables pre-treatment $(p>0.05)$. There was a significant decrease in $\mathrm{EEl}$ of experimental group compared with that of control group post treatment ( $p>0.001$ ). There was a significant increase in $6 \mathrm{MWT}$, anterior and lateral reaching tests of experimental group compared with that of control group post treatment ( $p>0.001)$.

\section{Discussion}

Increased EE may restrict the walking capacity of children with CP [43]. The strategy of treadmill training with partial to complete weight bearing improves balance and postural stability which are necessary for gait in human beings [44]. The current study assessed the effect of treadmill training on

Table 1. Comparison of subject characteristics between experimental and control groups.

\begin{tabular}{llllll}
\hline & $\begin{array}{l}\text { Experimental } \\
\text { group }\end{array}$ & $\begin{array}{l}\text { Control } \\
\text { group }\end{array}$ & & & \\
\hline & $\overline{\mathrm{x}} \pm$ SD & $\overline{\mathrm{x}} \pm$ SD & MD & t- value & p- value \\
\hline Age (years) & $9.27 \pm 0.59$ & $9.12 \pm 0.65$ & 0.15 & 0.89 & $0.37^{*}$ \\
Weight $(\mathrm{kg})$ & $27.86 \pm 1.44$ & $28.28 \pm 1.3$ & -0.42 & -1.07 & $0.28^{\star}$ \\
Height $(\mathrm{cm})$ & $105.11 \pm 4.73$ & $105.84 \pm 4.02$ & -0.73 & -0.58 & $0.56^{*}$ \\
BMI $\left(\mathrm{kg} / \mathrm{m}^{2}\right)$ & $25.33 \pm 2.25$ & $25.35 \pm 2.3$ & -0.02 & -0.03 & $0.97^{\star}$ \\
Boys $/ \mathrm{Girls}$ & $16 / 10$ & $14 / 11$ & -- & $(\chi 2=0.16)$ & $0.68^{*}$ \\
\hline
\end{tabular}

$\overline{\mathrm{x}}$, Mean; SD, Standard deviation; MD, Mean difference; $\chi 2$, Chi squared value; $\mathrm{p}$ value, Probability value; ${ }^{*}$, Non significant.

Table 2. Mean EEI, 6MWT, anterior and lateral reaching tests in study and control groups.

\begin{tabular}{|c|c|c|c|c|c|c|c|c|}
\hline & \multicolumn{3}{|l|}{ Pre treatment } & \multicolumn{5}{|l|}{ Post treatment } \\
\hline & $\begin{array}{l}\text { Experimental } \\
\text { group }\end{array}$ & $\begin{array}{l}\text { Control } \\
\text { group }\end{array}$ & & $\begin{array}{l}\text { Experimental } \\
\text { group }\end{array}$ & $\begin{array}{l}\text { Control } \\
\text { group }\end{array}$ & & $\begin{array}{l}\text { Pre vs post } \\
\text { (Experimental } \\
\text { group) }\end{array}$ & $\begin{array}{l}\text { Pre vs post } \\
\text { (Control } \\
\text { group) }\end{array}$ \\
\hline & $\overline{\mathrm{x}} \pm \mathrm{SD}$ & $\overline{\mathrm{x}} \pm \mathrm{SD}$ & p value & $\overline{\mathrm{x}} \pm \mathrm{SD}$ & $\overline{\mathrm{x}} \pm \mathrm{SD}$ & $p$ value & p value & p value \\
\hline EEI (beats/meter) & $1.16 \pm 0.24$ & $1.17 \pm 0.13$ & 0.89 & $0.68 \pm 0.28$ & $0.96 \pm 0.11$ & $0.001^{*}$ & $0.001^{*}$ & $0.001^{*}$ \\
\hline 6 MWT (meter) & $57.76 \pm 1.96$ & $57.04 \pm 2.18$ & 0.21 & $62.73 \pm 2.52$ & $59.36 \pm 2.73$ & $0.001^{*}$ & $0.001^{*}$ & $0.001^{*}$ \\
\hline Anterior reaching test $(\mathrm{cm})$ & $1.53 \pm 0.3$ & $1.52 \pm 0.32$ & 0.9 & $5.28 \pm 0.78$ & $3.96 \pm 0.87$ & $0.001^{\star}$ & $0.001^{\star}$ & $0.001^{*}$ \\
\hline Lateral reaching test $(\mathrm{cm})$ & $1.54 \pm 0.32$ & $1.47 \pm 0.31$ & 0.43 & $5.23 \pm 0.79$ & $3.78 \pm 0.42$ & $0.001^{*}$ & $0.001^{*}$ & $0.001^{*}$ \\
\hline
\end{tabular}

$\overline{\mathrm{x}}$, mean; SD, standard deviation; p-value, level of significance; ${ }^{\star}$ Significant. 
EC of walking, functional walking capacity and postural stability in children with hemiplegic CP. Both groups adequately completed treatment protocols over twelve-week period. These treatment protocols led to a within group significant increase in functional walking capacity, postural stability and significant decrease in EC of walking post-treatment compared with pre-treatment. The significant improvement in all measured outcomes was achieved via treatment protocol of the experimental group.

Treadmill exercise with [45] or without [46] support of body weight may enhance the walking speed of children with CP. Findings of Begnoche and Pitetti [45] and Hodapp et al. [46] may support the current significant increase in distance that was achieved on 6MWT in the experimental group after treatment. They concluded that treadmill training improves endurance and functional walking capacity in children with CP. Also, Han [47] found that balance; gross motor functions and speed of walking in children with CP improved by treadmill training.

According to the results of this study, physical therapy program with treadmill training is described to be more effective on improving postural stability. This is may be due to the effect of treadmill training on improving postural control ability and subsequently improving postural stability. This is supported by the finding of Grecco et al. [48] who mentioned that, treadmill walking contributes to postural control and stability by permitting rhythmical repetitions ofgait cycle and enhancing the control between both agonist and antagonist muscle groups. Furthermore, Damiano et al. [49] reported that treadmill training may facilitate the strength of lower limb muscles and postural control by, allowing neural adaptability that improves the efficiency of neuromuscular component in children with hemiplegia. Repetitive stepping on treadmill may enhance postural control by improving strength of quadriceps and hamstring muscles which in turn, improves kinesthetic and sensory awareness around the knee joint [50].

The significant decrease in EEl post treatment in the experimental group showed that, treadmill training may play an essential role inminimizing EE during walking. Thus, improving the efficiency of walking in children with CP.

According to Ortega and Farley [51], walking pattern in children with $\mathrm{CP}$ is characterized by low mechanical efficiency and, the recovery of energy of those children during ambulation is lower than developed typically children. This is due to higher displacement of center of mass (COM) and inefficient exchange between kinetic and potential energy. Also, Schuch and Peyre-Tartaruga [52] reported that in children with $\mathrm{CP}$, muscle spasticity or co-contraction of lower extremities increases EE during walking and leads to variation in the displacement of the COM.

Gage [53] reported that, there are five attributes of normal gait cycle (stability in stance phase, sufficient foot clearance in swing, proper prepositioning of the foot in swing phase, energy conservation and adequate step length) which minimize $\mathrm{EE}$ during walking. These attributes are absent in children with $\mathrm{CP}$, resulting in decrease their walking efficiency and increase EE.

The effect of treadmill training on decreasing EE during ambulation may be due to its effect on spasticity and improving muscle strength. This opinion is supported by Hess et al. [54] who illustrated that during treadmill walking, children can walk more symmetrically, with low spasticity and better cardiovascular performance.

Treadmill training improves balance activities and functional performance of children with CP [55]. Also, it is an important therapeutic modality for gait training in ambulatory children with CP who have higher EE and lower walking efficiency [56].

The current study has some limitations such as; the absence of follow-up for participants which may restrict the application of our results only on the short term effect of treadmill training. Additionally, the children who participated in this study were restricted to one type of $\mathrm{CP}$ with the age group from eight to ten years and on one level of GMFCS. So, similar studies are needed on other types of CP with different levels on GMFCS. A comparative study between the impact of treadmill training and unweighting system on $\mathrm{EE}$ is also recommended.

\section{Conclusion}

Based on the results of this study, treadmill training can improve EC of walking, functional walking capacity and postural stability in children with CP.So, treadmill training program may be used as an effective therapeutic modality to improve postural stability and walking efficiency in children with CP.

\section{Competing interests}

The authors declare that they have no competing interests.

Authors' contributions

\begin{tabular}{|l|c|c|}
\hline Authors' contributions & WEE & AMAE \\
\hline Research concept and design & $\checkmark$ & $\checkmark$ \\
\hline Collection and/or assembly of data & $\checkmark$ & $\checkmark$ \\
\hline Data analysis and interpretation & $\checkmark$ & $\checkmark$ \\
\hline Writing the article & $\checkmark$ & -- \\
\hline Critical revision of the article & $\checkmark$ & $\checkmark$ \\
\hline Final approval of article & $\checkmark$ & $\checkmark$ \\
\hline Statistical analysis & $\checkmark$ & -- \\
\hline
\end{tabular}

Acknowledgments

For all children and their parents who accepted to participate in this study. As well as I would like to thank everyone who contributed to children evaluation and random sample distribution of the current research.

\section{Publication history}

Editor: Gordon John Alderink, Grand Valley State University, USA. Received: 07-Feb-2019 Final Revised: 03-Apr-2019

Accepted: 05-Apr-2019 Published: 02-May-2019

\section{References}

1. Rosenbaum P, Paneth N, Leviton A, Goldstein M, Bax M, Damiano D, Dan $B$ and Jacobsson B. A report: the definition and classification of cerebral palsy April 2006. Dev Med Child Neurol Suppl. 2007; 109:8-14. | PubMed 
2. Bell KL and Davies PS. Energy expenditure and physical activity of ambulatory children with cerebral palsy and of typically developing children. Am J Clin Nutr. 2010; 92:313-9. | Article | PubMed

3. Furukawa $A$, Nii E, Iwatsuki $H$, Nishiyama $M$ and Uchida A. Factors of Influence on the Walking Ability of Children with Spastic Cerebral Palsy. J PhysTherSci. 1998; 10:1-5.

4. Sankar C and Mundkur N. Cerebral palsy-definition, classification, etiology and early diagnosis. Indian J Pediatr. 2005; 72:865-8. | PubMed

5. Woollacott MH and Shumway-Cook A. Postural dysfunction during standing and walking in children with cerebral palsy: what are the underlying problems and what new therapies might improve balance? Neural Plast. 2005; 12:211-9; discussion 263-72. | Article | PubMed Abstract | PubMed FullText

6. Norman JF, Bossman S, Gardner P and Moen C. Comparison of the energy expenditure index and oxygen consumption index during self-paced walking in children with spastic diplegia cerebral palsy and children without physical disabilities. Pediatr Phys Ther. 2004; 16:20611. | Article | PubMed

7. van den Hecke A, Malghem C, Renders A, Detrembleur C, Palumbo S and Lejeune TM. Mechanical work, energetic cost, and gait efficiency in children with cerebral palsy. J Pediatr Orthop. 2007; 27:643-7. | Article I PubMed

8. Campbell $\mathrm{J}$ and Ball J. Energetics of walking in cerebral palsy. Orthop Clin North Am. 1978; 9:374-7. I PubMed

9. Duffy CM, Hill AE, Cosgrove AP, Corry IS and Graham HK. Energy consumption in children with spina bifida and cerebral palsy: a comparative study. Dev Med Child Neurol. 1996; 38:238-43. | Article | PubMed

10. Rose J, Gamble JG, Burgos A, Medeiros J and Haskell WL. Energy expenditure index of walking for normal children and for children with cerebral palsy. Dev Med Child Neurol. 1990; 32:333-40. | Article | PubMed

11. Unnithan VB, Dowling JJ, Frost $\mathrm{G}$ and Bar-Or O. Role of cocontraction in the $\mathbf{O} 2$ cost of walking in children with cerebral palsy. Med Sci Sports Exerc. 1996; 28:1498-504. | Article | PubMed

12. Keefer DJ, Tseh W, Caputo JL, Apperson K, McGreal S and Morgan DW. Comparison of direct and indirect measures of walking energy expenditure in children with hemiplegic cerebral palsy. Dev Med Child Neurol. 2004; 46:320-4. | Article | PubMed

13. Johnston TE, Moore SE, Quinn LT and Smith BT. Energy cost of walking in children with cerebral palsy: relation to the Gross Motor Function Classification System. Dev Med Child Neurol. 2004; 46:34-8. | Article | PubMed

14. Brehm MA, Harlaar J and Schwartz M. Effect of ankle-foot orthoses on walking efficiency and gait in children with cerebral palsy. J Rehabil Med. 2008; 40:529-34. | Article | PubMed

15. Katsumi $\mathrm{M}$ et al. An applied gait training of disabled children with spastic paralysis and its evaluation. Sogo Rehabilitation. 1990; 18:39-44.

16. Bottos M, Feliciangeli A, Sciuto L, Gericke $C$ and Vianello A. Functional status of adults with cerebral palsy and implications for treatment of children. Dev Med Child Neurol. 2001; 43:516-28. | Article | PubMed

17. Liao HF and Hwang AW. Relations of balance function and gross motor ability for children with cerebral palsy. Percept Mot Skills. 2003; 96:1173-84. | Article | PubMed

18. Woollacott M, Shumway-Cook A, Hutchinson S, Ciol M, Price R and Kartin D. Effect of balance training on muscle activity used in recovery of stability in children with cerebral palsy: a pilot study. Dev Med Child Neurol. 2005; 47:455-61. | PubMed

19. Kenis-Coskun O, Giray E, Eren B, Ozkok O and Karadag-Saygi E. Evaluation of postural stability in children with hemiplegic cerebral palsy. J Phys Ther Sci. 2016; 28:1398-402. | Article | PubMed Abstract | PubMed FullText

20. Cernak K, Stevens V, Price R and Shumway-Cook A. Locomotor training using body-weight support on a treadmill in conjunction with ongoing physical therapy in a child with severe cerebellar ataxia. Phys Ther. 2008; 88:88-97. | Article | PubMed
21. Mattern-Baxter K, Bellamy S and Mansoor JK. Effects of intensive locomotor treadmill training on young children with cerebral palsy. Pediatr Phys Ther. 2009; 21:308-18. | Article | PubMed

22. Bohannon $R$ and Smith MB. Inter-reliability of modified Ashwerth scale of muscle spasticity. PhysTher. 1987; 67:206-208.

23. Palisano R, Rosenbaum P, Walter S, Russell D, Wood E and Galuppi B. Development and reliability of a system to classify gross motor function in children with cerebral palsy. Dev Med Child Neurol. 1997; 39:214-23. | Article | PubMed

24. Rose J, Gamble JG, Medeiros J, Burgos A and Haskell WL. Energy cost of walking in normal children and in those with cerebral palsy: comparison of heart rate and oxygen uptake. J Pediatr Orthop. 1989; 9:276-9. | PubMed

25. Butler P, Engelbrecht M, Major RE, Tait JH, Stallard J and Patrick JH. Physiological cost index of walking for normal children and its use as an indicator of physical handicap. Dev Med Child Neurol. 1984; 26:607-12. I Article I PubMed

26. Rose J, Gamble JG, Lee J, Lee R and Haskell WL. The energy expenditure index: a method to quantitate and compare walking energy expenditure for children and adolescents. J Pediatr Orthop. 1991; 11:571-8. | PubMed

27. Strifling KM, Lu N, Wang M, Cao K, Ackman JD, Klein JP, Schwab JP and Harris GF. Comparison of upper extremity kinematics in children with spastic diplegic cerebral palsy using anterior and posterior walkers. Gait Posture. 2008; 28:412-9. | Article | PubMed

28. Maher CA, Williams MT and Olds TS. The six-minute walk test for children with cerebral palsy. Int J Rehabil Res. 2008; 31:185-8. | Article I PubMed

29. Solway S, Brooks D, Lacasse $Y$ and Thomas $S$. A qualitative systematic overview of the measurement properties of functional walk tests used in the cardiorespiratory domain. Chest. 2001; 119:256-70. | Article | PubMed

30. Vinchhi R, Diwan SH, Shah S and Vyas N. Test-retest reliability of six minute walk test in spastic ambulatory children with cerebral palsy. Int $J$ Contemp Pediatrics. 2014; 1:10-13.

31. American Thoracic Society Statement. Guidelines for the Six-Minute Walk Test. Am J Respir Crit Care Med. 2002; 166:111-117.

32. Bartlett $D$ and Birmingham $T$. Validity and reliability of a pediatric reach test. Pediatr Phys Ther. 2003; 15:84-92. I Article | PubMed

33. Volkman KG, Stergiou N, Stuberg W, Blanke D and Stoner J. Methods to improve the reliability of the functional reach test in children and adolescents with typical development. Pediatr Phys Ther. 2007; 19:20-7. | Article | PubMed

34. Deshmukh AA, Ganesan S and Tedla JS. Normal values of functional reach and lateral reach tests in Indian school children. Pediatr Phys Ther. 2011; 23:23-30. | Article | PubMed

35. Brauer $S$, Burns $Y$ and Galley P. Lateral reach: a clinical measure of medio-lateral postural stability. Physiother Res Int. 1999; 4:81-8. | Article I PubMed

36. Niznik T, Turner $D$ and Worrell T. Functional reach as a measurment of balance for children with lower extremity spasticity. Phys.Occup.Ther. Pediat. 1995; 15:1-16.

37. Scrutton D, Damiano D and Mayston M. Management of the Motor Disorders of Children with Cerebral Palsy (Clinics in Developmental Medicine). London, England, Mac Keith Press. 2004.

38. Cherng RJ, Liu CF, Lau TW and Hong RB. Effect of treadmill training with body weight support on gait and gross motor function in children with spastic cerebral palsy. Am J Phys Med Rehabil. 2007; 86:548-55. | Article I PubMed

39. Schindl MR, Forstner C, Kern $\mathrm{H}$ and Hesse S. Treadmill training with partial body weight support in nonambulatory patients with cerebral palsy. Arch Phys Med Rehabil. 2000; 81:301-6. | Article I PubMed

40. Day JA, Fox EJ, Lowe J, Swales HB and Behrman AL. Locomotor training with partial body weight support on a treadmill in a nonambulatory child with spastic tetraplegic cerebral palsy: a case report. Pediatr Phys Ther. 2004; 16:106-13. | Article | PubMed 
41. Dodd KJ and Foley S. Partial body-weight-supported treadmill training can improve walking in children with cerebral palsy: a clinical controlled trial. Dev Med Child Neurol. 2007; 49:101-5. | Article | PubMed

42. Provost B, Dieruf K, Burtner PA, Phillips JP, Bernitsky-Beddingfield A, Sullivan KJ, Bowen CA and Toser L. Endurance and gait in children with cerebral palsy after intensive body weight-supported treadmill training. Pediatr Phys Ther. 2007; 19:2-10. | Article | PubMed

43. Unnithan VB, Clifford $C$ and Bar-Or O. Evaluation by exercise testing of the child with cerebral palsy. Sports Med. 1998; 26:239-51. | Article | PubMed

44. Finch $L$ and Barbeau $H$. Hemiplegic gait: new treatment strategies. Physiother Can. 1986; 38:36-41.

45. Begnoche DM and Pitetti KH. Effects of traditional treatment and partial body weight treadmill training on the motor skills of children with spastic cerebral palsy. A pilot study. Pediatr Phys Ther. 2007; 19:11-9. | Article I PubMed

46. Hodapp M, Vry J, Mall V and Faist M. Changes in soleus H-reflex modulation after treadmill training in children with cerebral palsy. Brain. 2009; 132:37-44. | Article | PubMed

47. Han HK. The effect of task-oriented training on the assessment of gross motor functions, balance and walking in children with cerebral palsy. Sahmyook University. Dissertation ofMaster's Degree. 2009.

48. Grecco LA, Tomita SM, Christovao TC, Pasini H, Sampaio LM and Oliveira CS. Effect of treadmill gait training on static and functional balance in children with cerebral palsy: a randomized controlled trial. Braz J Phys Ther. 2013; 17:17-23. | Article | PubMed

49. Damiano DL, Alter KE and Chambers $\mathrm{H}$. New clinical and research trends in lower extremity management for ambulatory children with cerebral palsy. Phys Med Rehabil Clin N Am. 2009; 20:469-91. | Article | PubMed Abstract | PubMed FullText

50. Duncan W, Sullivan J, Behrman L and Azen P et al. Bodyweightsupported treadmill rehabilitation after stroke. N Engl J Med. 2011; 364:2026-2036.

51. Ortega JD and Farley CT. Minimizing center of mass vertical movement increases metabolic cost in walking. J Appl Physiol (1985). 2005; 99:2099-107. | Article | PubMed

52. Schuch $C$ and Peyre-Tartaruga L. Locomotion in children with cerebral palsy: a review with special reference to the displacement of center of mass and energy cost. Cienciaen Movimento. 2010; 23:21-27.

53. Gage J. Gait analysis in Cerebral Palsy. Mac Keith Press. 1991; 101.

54. Hesse S, Werner $C$, von Frankenberg $S$ and Bardeleben A. Treadmill training with partial body weight support after stroke. Phys Med Rehabil Clin N Am. 2003; 14:S111-23. | Article | PubMed

55. Cho $C$, Hwang W, Hwang $S$ and Chung Y. Treadmill Training with Virtual Reality Improves Gait, Balance, and Muscle Strength in Children with Cerebral Palsy. Tohoku J Exp Med. 2016; 238:213-8. I Article I PubMed

56. Kim OY, Shin YK, Yoon YK, Ko EJ and Cho SR. The effect of treadmill exercise on gait efficiency during overground walking in adults with cerebral palsy. Ann Rehabil Med. 2015; 39:25-31. | Article | PubMed Abstract | PubMed FullText

Citation:

Abd El-nabie WAE and Abd El-Monem AM. Effect of Treadmill Training on Energy Cost of Walking, Functional walking capacity and Postural Stability in Children with Cerebral Palsy:A Randomized Controlled Trial. Phys Ther Rehabil. 2019; 6:5. http://dx.doi.org/10.7243/2055-2386-6-5 